\title{
Unregulated private markets for health care in Canada? Rules of professional misconduct, physician kickbacks and physician self-referral
}

\author{
Sujit Choudhry, Niteesh K. Choudhry, Adalsteinn D. Brown
}

ß See related article page 1119

T

The regulation of private health care has become a central issue in Canadian health policy. The legality of private markets for medical services already available under public health insurance has attracted attention. ${ }^{1}$ However, there has been little discussion of the regulation of independent health facilities (IHFs). ${ }^{2} \mathrm{IHFs}$ are privately owned, for-profit entities that provide therapeutic and diagnostic services, such as physiotherapy and laboratory testing, and operate both within and outside the public system. There may be 1000 IHFs in Ontario alone. ${ }^{2}$

IHFs depend on physician referrals for patients. This raises 2 important issues. First, IHFs can compensate physicians for patient referrals (a kickback), a practice that can potentially distort clinical judgement. Second, physicians can make referrals to IHFs that they themselves own, raising similar concerns. Both problems have occurred in the United States and have prompted regulation., ${ }^{3,4}$ But, in spite of the US experience, kickbacks and self-referral were not mentioned in the Kirby ${ }^{5}$ and Romanow ${ }^{6}$ reports and have generated limited scholarly commentary in Canada.

Financial conflicts of interest involving physicians are regulated by common law, which imposes a fiduciary duty on physicians toward patients. ${ }^{8,9}$ Canadian courts have stated that physicians fulfill this duty by disclosing conflicting interests to patients. ${ }^{10,11}$ Unfortunately, in most clinical settings disclosure provides inadequate protection for patients.

The courts acknowledge that the professional regulatory bodies such as the provincial colleges of physicians and surgeons may have the greatest expertise in governing conflict of interest. ${ }^{12}$ Therefore, we review the rules governing financial relationships between physicians and IHFs as found in provincial codes of professional conduct for physicians. In some respects, these rules adequately protect patients; in others, they do not. We propose regulatory models to be implemented before the further proliferation of IHFs.

\section{Defining kickbacks and self-referral}

The term kickback refers to the financial compensation of physicians for patient referrals. Compensation can flow from IHFs to referring physicians, or from specialists to primary care physicians (fee-splitting). Compensation can consist of cash payments for each referral, discounted office space or leases for medical equipment, or business loans at below-market rates.

Compensation for referrals is unobjectionable in most markets, but is problematic in health care in view of the potential conflict between physicians' financial self-interest and their duty to advise patients solely on the basis of health needs. Kickbacks have the potential to entice physicians to make unnecessary referrals, or to refer patients to particular providers for reasons other than the quality or accessibility of care. Moreover, incentives to increase referral volume and to direct referral streams may create inefficiencies by increasing waiting times, decreasing access and potentially increasing costs.

The term self-referral refers to a situation in which physicians own the IHFs to which they make referrals and thus stand to benefit financially from the IHFs' profits. This practice has generated more debate than kickbacks have. ${ }^{13}$ Some physicians argue that physician-owned IHFs are simply extensions of physician practices in a different physical location, whether or not the referring physician personally provides services at those facilities. Defenders of self-referral also argue that ownership by referring physicians may be a warrant of quality..$^{14}$

US data suggest that physician ownership of IHFs increases the number of referrals and leads to higher costs. ${ }^{15}$ Physicians who owned and operated diagnostic imaging equipment in their offices were up to 7 times more likely to obtain radiologic examinations than were physicians who always referred patients to radiologists. ${ }^{16,17}$ In addition, the charges per episode of care were significantly higher for self-referring physicians. Moreover, the existing data on quality suggest that the purported benefits of self-referral for quality may not exist. For example, licensed physiotherapists spent significantly less time per visit treating patients in physician-owned facilities than in other facilities. ${ }^{18}$

\section{Rules of professional conduct}

To determine the regulatory framework in Canada, we reviewed provincial laws and regulations (rules) governing the practice of medicine listed in an electronic legal database (Quicklaw) and on the Web sites of provincial med- 
ical licensing authorities. For kickbacks, we coded rules according to whose conduct is regulated, what conduct is regulated, how that conduct is regulated and whether exceptions are permitted. For self-referrals to health facilities, we coded rules according to whose conduct is regulated, how the conduct is regulated and whether exceptions are permitted.

\section{Kickbacks}

Table 1 summarizes rules of physician professional misconduct governing kickbacks. Eight provinces explicitly regulate kickbacks. Although 2 provinces (Nova Scotia and Prince Edward Island) do not explicitly prohibit kickbacks, a general prohibition on professional misconduct could potentially be legally interpreted to prohibit kickbacks.

Provisions against kickbacks vary in their scope. Seven provinces prohibit receiving any kickback, whereas Quebec prohibits the receipt of kickbacks only if the kickback "would jeopardize ... [the] professional independence" of a physician, ${ }^{26}$ without further definition. Seven provinces regulate referrals to physicians, IHFs, pharmaceutical suppliers and medical device suppliers, often through general language that does not distinguish among different kinds of referrals. In contrast, British Columbia regulates only those referrals made to suppliers of pharmaceuticals and medical devices.

Four provinces allow for rental agreements between physicians and parties (e.g., other physicians, IHFs, phar- macies and medical device suppliers) to whom those physicians may refer. Rental arrangements can disguise kickbacks by setting leases at below-market rates (where referring physicians are tenants) or above-market rates (where referring physicians are landlords), or by tying rental rates to referral volume. Rental arrangements are therefore permissible only if rent is set at market rates and contains no volume incentive for referrals.

Finally, Quebec permits physicians to receive royalties for prescribing "products having a benefit to health," if those royalties are disclosed to patients. ${ }^{27}$ This provision is broad enough to cover pharmaceuticals and medical devices and could contradict Quebec's more general provision on kickbacks.

\section{Physician self-referral}

Table 2 summarizes rules of physician professional misconduct on self-referral. Seven provinces regulate selfreferral to IHFs in which referring physicians have personally invested. In addition, 4 provinces regulate referrals to health facilities in which "immediate" family members have invested, since it would be easy to circumvent such rules by putting investments in the name of a spouse, child or parent. Three provinces also regulate referrals to IHFs in which "extended" family members have invested. Although 3 provinces (Newfoundland, Nova Scotia and Prince Edward Island) do not expressly regulate selfreferral, a general prohibition on professional misconduct

\begin{tabular}{|c|c|c|c|c|c|c|c|c|}
\hline Variable & $\mathrm{BC}^{19}$ & $A B^{20}$ & $\mathrm{SK} \dagger^{21,22}$ & $M B t^{23,24}$ & $\mathrm{ON}^{25,26}$ & QC $\ddagger^{27,28}$ & $\mathrm{NB}^{29}$ & $\mathrm{NL}^{30}$ \\
\hline \multicolumn{9}{|l|}{ Party to kickback arrangement } \\
\hline Physician as payor of kickback & & $X$ & $x$ & & $X$ & $X$ & $x$ & \\
\hline Physician as recipient of kickback & $x$ & $x$ & $x$ & $x$ & $x$ & $x$ & $x$ & $x$ \\
\hline Any person as payor of kickback & & $x$ & $x$ & $x$ & $x$ & $x$ & $x$ & \\
\hline Drug/device supplier as payor of kickback & $\mathrm{x}$ & & $\mathrm{x}$ & $\mathrm{x}$ & $\mathrm{x}$ & & & $x$ \\
\hline \multicolumn{9}{|l|}{ Which referrals are regulated? } \\
\hline To physicians & & $x$ & $x$ & $x$ & $x$ & $x$ & $x$ & $x$ \\
\hline To IHFs & & $X$ & $x$ & $x$ & $x$ & $X$ & $x$ & $x$ \\
\hline To pharmaceutical suppliers & $x$ & $X$ & $\mathrm{x}$ & $X$ & $X$ & $X$ & $x$ & $X$ \\
\hline To medical device suppliers & $x$ & $x$ & $x$ & $x$ & $x$ & $x$ & $x$ & $x$ \\
\hline \multicolumn{9}{|l|}{ How are kickbacks regulated? } \\
\hline Disclosure & & & & & & $x$ & & \\
\hline Prohibition & $x$ & $x$ & $x$ & $x$ & $x$ & $x$ & $x$ & $x$ \\
\hline \multicolumn{9}{|l|}{ Exceptions§ } \\
\hline Market value rentals and no volume incentive & & & $x$ & $x$ & $x$ & & & $x$ \\
\hline \multicolumn{9}{|c|}{$\begin{array}{l}\text { Note: IHFs = independent health facilities. } \\
\text { "Nova Scotia and Prince Edward Island have no specific regulations on physician kickbacks and are thus excluded from this table. } \\
\text { +Saskatchewan, Manitoba and Ontario each have } 2 \text { provisions governing kickbacks. One provision prohibits kickbacks in general language. The } \\
\text { second provision is also wide-ranging but has more specific rules. } \\
\text { fQuebec has } 2 \text { provisions governing kickbacks. One provision prohibits the receipt of a kickback, but only if the kickback "would jeopardize ... [the] } \\
\text { professional independence" of a physician. (No further definition of the amount or nature of such a kickback is provided.) The other provision permits } \\
\text { the physician to receive royalties for prescribing "products having a benefit to health," provided those royalties are disclosed to patients. } \\
\text { SThese exceptions allow for rental agreements at market value between physicians and parties (i.e., physicians, IHFs, pharmacies, medical device } \\
\text { suppliers) to whom those physicians may make referrals. }\end{array}$} \\
\hline
\end{tabular}


could potentially be legally interpreted to prohibit kickbacks.

Provinces regulate self-referral differently. Four provinces prohibit self-referral, whereas 3 provinces simply require that referring physicians disclose investment interests to patients. Four provinces permit self-referral in limited circumstances, such as in communities where there is no IHF that does not raise conflict-of-interest concerns. (This may be important in rural areas.)

Finally, 2 provinces prohibit physician investment in IHFs to include volume incentives for referrals. In contrast, volume incentives are permitted in 2 provinces that allow self-referral with disclosure, and in the 3 provinces where self-referral is not regulated.

\section{Discussion and policy recommendations}

Although some provinces have rules of professional conduct governing kickbacks and self-referrals, these rules are often inadequate. Regardless, all provinces should enact clear provisions.

\section{Kickbacks}

Although 8 provinces prohibit physicians from receiving kickbacks, only 5 prohibit physicians from paying or offering to pay kickbacks. But paying kickbacks represents a conflict of interest in that this action seeks to in- duce referrals regardless of patient health status. Moreover, the growing role of nonphysician health care professionals (e.g., physiotherapists) who may direct patients to physicians strengthens the case for prohibiting the payment of kickbacks by physicians. All provinces should prohibit physicians from offering to pay, paying or receiving kickbacks - not only to physicians, but also to any other person.

\section{Physician self-referral}

Three provinces do not expressly regulate self-referral to health facilities. Furthermore, 6 others permit selfreferrals by physicians to IHFs owned by members of their immediate family. Given the cost and quality concerns raised by self-referral, and the ease of circumventing restrictions on self-referral through placing investments in the names of immediate family, provincial rules should be amended.

Three provinces that regulate self-referral merely require disclosure by referring physicians to patients of their investment interest. Although disclosure may effectively police financial conflict of interest if such disclosure is made to someone able to make an independent judgement (e.g., to physicians in the case of medical research), disclosure to relatively inexpert patients does not work, particularly when they require treatment. Patients may also interpret disclosure not as a warning to take care, but rather as a warranty

Table 2: Extent of regulation of physician self-referral, by province*

\begin{tabular}{|c|c|c|c|c|c|c|c|}
\hline Variable & $\mathrm{BC}^{31,32}$ & $\mathrm{AB} \dagger^{33}$ & $\mathrm{SK}^{34}$ & $M B \ddagger^{24,35}$ & $\mathrm{ON}^{36}$ & $\mathrm{QC}^{37}$ & $\mathrm{NB}^{38}$ \\
\hline \multicolumn{8}{|l|}{ Who has investment interest? } \\
\hline Physicians & $X$ & $X$ & $X$ & $X$ & $X$ & $X$ & $X$ \\
\hline Immediate family§ & $x$ & & $X$ & X㧊 & $x$ & & \\
\hline Extended family & $X$ & & $X$ & & $X$ & & \\
\hline \multicolumn{8}{|l|}{ How is self-referral regulated? } \\
\hline Disclosure & & & & $X$ & $X$ & $X$ & \\
\hline Prohibition & $X$ & $X$ & $X$ & & & & $X$ \\
\hline Restrictions on investment income & & $X$ & & $X$ & & & \\
\hline Other & & & & $X$ & & & \\
\hline \multicolumn{8}{|l|}{ Exceptions } \\
\hline Otherwise not available / community need** & $X$ & $X$ & & & & & \\
\hline Medically necessary†† & & $X$ & $X$ & & & & \\
\hline Publicly traded corporation not closely held & & & & & $X \S \S$ & & \\
\hline \multicolumn{8}{|c|}{ 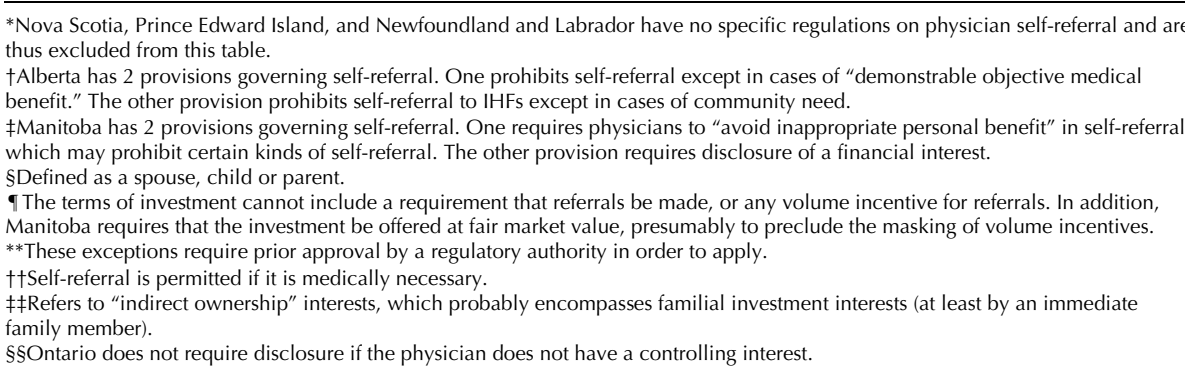 } \\
\hline
\end{tabular}


of an IHF's quality. ${ }^{13}$ Finally, patients might not wish to refuse the referral, for fear of straining the physicianpatient relationship.

Self-referral should be prohibited. However, there should be a "community-need" exception, perhaps employing techniques such those used to define underserviced areas. Prior approval by a regulatory authority would prevent abuse. A ban on self-referral would still permit physician investment in IHFs. Finally, a ban on self-referral, even with a community-need exception, would require reconsideration if governments encourage them to financially integrate with IHFs or hospitals (e.g., through risk-adjusted capitation). The goal of financial integration is to align providers' incentives in order to encourage them to provide care as costeffectively as possible. However, financial integration between physicians and IHFs would make self-referral difficult to avoid. Provincial governments would need to create exceptions to the prohibition on self-referral, as has happened in the United States. ${ }^{38}$

If self-referral is permitted, the terms of physician investment must not create incentives either to make referrals or to inflate referrals. Only 2 provinces impose such restrictions at present.

\section{Conclusion}

Although provinces have attempted to regulate against physician kickbacks and self-referral, the current regulatory framework is inadequate. As IHFs proliferate, provincial governments should review current rules to "get in front" of the important regulatory challenges that IHFs pose to cost and quality.

This article has been peer reviewed.

From the Faculty of Law, University of Toronto (S. Choudhry); the Joint Centre for Bioethics (S. Choudhry); the Departments of Medicine (N. Choudhry) and of Health Policy, Management, and Evaluation (Brown), Faculty of Medicine, University of Toronto, Toronto, Ont.; the Department of Medicine, University Health Network (N. Choudhry), Toronto, Ont.; and the Department of Medicine, Brigham and Women's Hospital, Harvard Medical School and the PhD Program in Health Care Policy, Harvard University, Boston, Mass. (N. Choudhry)

Competing interests: None declared.

Contributions: All authors contributed substantially to the drafting and revision of this manuscript and have given final approval for this version to be published.

Acknowledgements: Niteesh Choudhry is supported by a Frank Knox Scholarship from Harvard University and a Canadian Institutes of Health Research Post-Doctoral Fellowship.

\section{References}

1. Flood CM, Archibald T. The illegality of private health care in Canada. CMA7 2001;164(6):825-30.

2. Gilmour JN. Regulation of free-standing health facilities: an entrée for privatization and for-profit in health care. Health Law 7 2003;S131-S152.

3. 42 United States Code $\$ 1320 \mathrm{a}-7 \mathrm{~b}$ (1998).

4. Ethics in Patient Referral Act, 42 United States Code $\$ 1395 \mathrm{nn}$ (1998).

5. Standing Committee on Social Affairs, Science and Technology. The bealth of Canadians - the federal role. Volume 2: current trends and future challenges. Ottawa: The Committee; 2002.

6. Commission on the Future of Health Care in Canada. Building on values: the future of health care in Canada. Saskatoon: The Commission; 2002.

7. Litman M. Fiduciary law and for-profit and not-for-profit health care. In Caulfield TA, von Tigerstrom B, editors. Health care reform and the law in Canada: meeting the challenge. Edmonton: University of Alberta Press; 2002. p. 85-130.

8. McInerney v. MacDonald (1992) 93 D.L.R. (4th) 415.

9. Dickens BM. Case comment on McInerney v. MacDonald. Can Bar Rev 1995 $73: 234-42$.

10. Dickens BM. Conflicts of interest in Canadian health care law. Am 7 Law Med 1995;21:259-80.

11. Henderson v. Fohnston (1956) 5 DLR (2d) 524 (Ont HC).

12. Cox v. College of Optometrists of Ontario (1988) 65 OR 461 (Ont HC).

13. Morreim EH. Conflicts of interest: profits and problems in physician referrals. FAMA 1989;262:390-4.

14. American Medical Association Council on Ethical and Judicial Affairs. Conflicts of interest. Physician ownership of medical facilities. 7AMA 1992;267:2366-9.

15. Mitchell JM, Sunshine JH. Consequences of physicians ownership of health care facilities — joint ventures in radiation therapy. N Engl 7 Med 1992;327:1497-501.

16. Hillman BJ, Joseph CA, Mabry MR, Sunshine JH, Kennedy SD, Noether M. Frequency and costs of diagnostic imaging in office practice - a comparison of selfreferring and radiologist-referring physicians. NEngl 7 Med 1990;323:1604-8.

17. Hillman BJ, Olson GT, Griffith PE, Sunshine JH, Joseph CA, Kennedy SD, et al. Physicians' utilization and charges for outpatient diagnostic imaging in a Medicare population. 7AMA 1992;268:2050-4.

18. Mitchell M, Scott E. Physician ownership of physical therapy services: effects on charges, utilization, profits, and service characteristics. 7AMA 1992;268:2055-9.

19. Medical Practitioners Act RSBC 1996, c 285, s 90.

20. By-laws of College of Physicians and Surgeons of Alberta, ss 48 and 51.1

21. By-laws, Saskatchewan College of Physicians and Surgeons, s 51(2)(n).

22. By-laws, Saskatchewan College of Physicians and Surgeons, s 51(1)(f)(i).

23. By-law 1, College of Physicians and Surgeons of Manitoba, Schedule G, s 53.

24. General Ethical Statement 124 (Conflict of Interest), College of Physicians and Surgeons of Manitoba.

25. Professional Misconduct Regulation, O Reg 856/93 as am., s. 11 .

26. General Regulation - Medicine Act, O Reg 114/94, s. 15 and 16.

27. Code of Ethics of Physicians, RSQ, c. M-9, r 4.1, s 73.

28. Code of Ethics of Physicians, RSQ, c. M-9, r 4.1, s 79.

29. Regulation 9, College of Physicians and Surgeons of New Brunswick, s 35 .

30. Medical Board Regulations, Nf Reg. 1113/96, ss 16 \& 17.

31. Medical and Health Care Services Regulation, BC Reg. 426/97, ss. 38-40.

32. Medicare Protection Act, RSBC c. 286, s. 35(1).

33. By-Laws of College of Physicians and Surgeons of Alberta, $\mathrm{s} 47$ and 49

34. By-Laws, Saskatchewan College of Physicians and Surgeons, s 51(1)(f)(iv) (diagnostic facilities).

35. By-Law 1, College of Physicians and Surgeons of Manitoba, Schedule G, s. 55.

36. General Regulation - Medicine Act, O Reg 114/94, s. 17.

37. Code of Ethics of Physicians, RSQ, c. M-9, r. 4.1, s. 77

38. Regulation 9, College of Physicians and Surgeons of New Brunswick, s. 36

39. 42 Code of Federal Regulations $\$ 411.355(\mathrm{c})$.

Correspondence to: Prof. Sujit Choudhry, Faculty of Law, University of Toronto, 78 Queen's Park, Toronto, ON M5S 2C5; fax 416 978-2648; sujit.choudhry@utoronto.ca 